\title{
多孔硅发光机理的研究
}

\author{
周咏东 金亿錐 宁永强 元金山
}

(中国科学院长春物理研究所, 长春 130021)

\section{关键词多孔硅、荧光粉、光致发光、扫描电镜、X 射线光电子谱}

\section{1 引言}

自从 Canham 报道了多孔硅的高效可见光发射后, 国内外许多研究组开展了对多孔硅发 光的研究. 人们希望利用多孔硅的高效可见光发射弥补硅材料低带隙、间接带的弱点, 实现 廉价的全硅光电集成, 同时可以制备廉价的显示器件. 虽然已有人制备出了多孔硅光探测 器、电致发光器件, 但对多孔硅可见光发射现象产生的机理还在进一步研究之中。一种观点 认为是由于多孔硅形成了纳米量级的硅柱造成的量子限制效应引起的高效可见光发射 ${ }^{[1]}$; 近 来有人提出是由于其中的硅氧烯 (Siloxene) 发光所致 ${ }^{[2]}$; 当然还有一些其它看法, 至今未成定 论. 多孔硅光致发光光谱谱带很宽, 半高宽 (FWHM) 一般在 $100-140 \mathrm{~nm}$ 之间, 峰值位置一 般在 600-700 $\mathrm{nm}^{[3]}$, 其 Raman 散射谱中有一特征振动峰在 $510 \mathrm{~cm}^{-1}$ 附近 ${ }^{[4]}$. 其表面特征结 构常为微米长微柱状. 本文报道了对用常规方法制备出的发光多孔硅进行的光谱实验研究, 进而从发光样品表面用非化学方法获得了黄色粉末状荧光物质, 粉末的光致发光光谱和原多 孔硅样品的光致发光光谱有相近的峰值位置、线型和半高宽, 且不易溶于水、乙醇、丙酮等常 见溶剂, 研磨后仍能发光. 扫描电镜的微结构研究和 X 射线光电子谱的组分分析结果也支持 多孔硅的高效可见光发射源于其制备过程中产生的粉末状发光物质.

\section{2 实验方法}

\section{1 样品制备}

所用单晶硅片为电阻率在 $2.4-3.6 \Omega \cdot \mathrm{cm}$ 的 $\mathrm{n}$ 型硅, 发光多孔硅制备工艺与文献中报道 的相同 ${ }^{[3]}$ (样品制备过程中用 $250 \mathrm{~W}$ 红外灯照射样品表面). 多孔硅表面的粉末状物质可以用 机械方法从吹干的样品表面轻轻取下. 粉末的研磨是用玛瑙研针完成的.

\section{2 光谱测试}

光致发光光谱, 用氮分子激光器产生的峰值输出功率为几百千瓦, 波长为 $337 \mathrm{~nm}$, 眿宽为 $10 \mathrm{~ns}$ 的脉冲式激光激发样品, 样品发出的苂光经过 Spex 1403 型光谱仪分光后由 R928 型光电 倍增管接收转变成电信号, 用 PARC162 型 Boxcar 对信号进行检测放大后输人计算机中进行 处理、绘图.

1993-03-26 收稿, 1993-12-30 收修改稿. 
Raman 散射光谱、用 $\mathrm{Ar}^{+}$激光器发出的 $488 \mathrm{~nm}$ 激光照射样品, 用 JY-T800 型激光 Raman 光谱仪对样品进行 Raman 光谱的测定 (所有光谱实验均在室温下进行).

\section{3 结构分析}

多孔硅表面形貌、截面结构以及发光粉末形貌分析照片是通过 $1000 \mathrm{~B}$ 型扫描电镜摄制的.

\section{4 组分分析}

样品表面组分分析是在 ESCALAB-MKII 型 X 射线光电子谱仪中实现的.

\section{3 结果 与 讨 论}

图 1-1 为多孔硅样品光致发光光谱图, 从图中看出其峰值位置在 $17260 \mathrm{~cm}^{-1}(580 \mathrm{~nm})$ 处, 半高宽为 $3600 \mathrm{~cm}^{-1}(122 \mathrm{~nm})$. 图 2 为多孔硅样品 Raman 散射谱, 图中在 $520 \mathrm{~cm}^{-1}$ 处有一较 窄的振动峰.

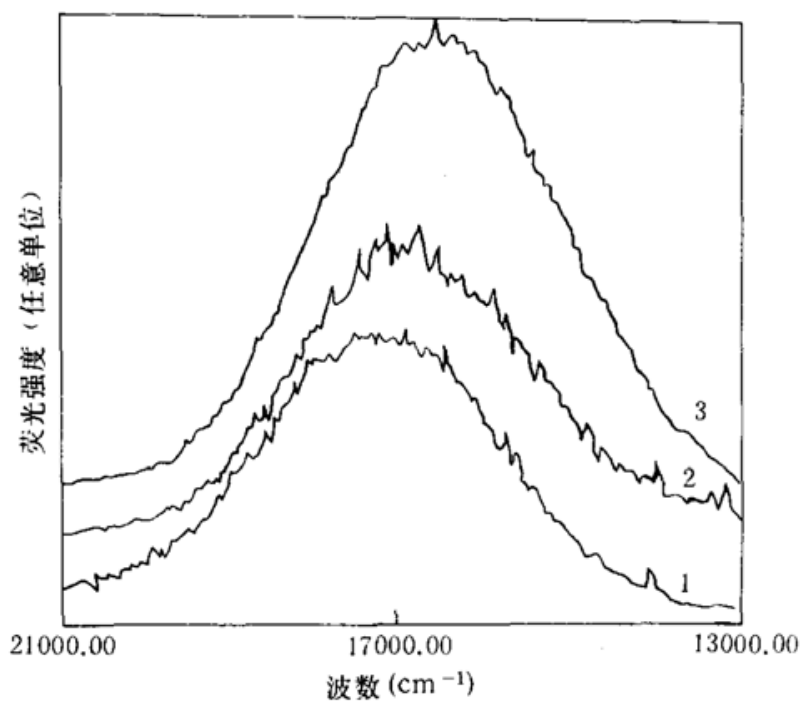

图 1 样品光致发光光谱

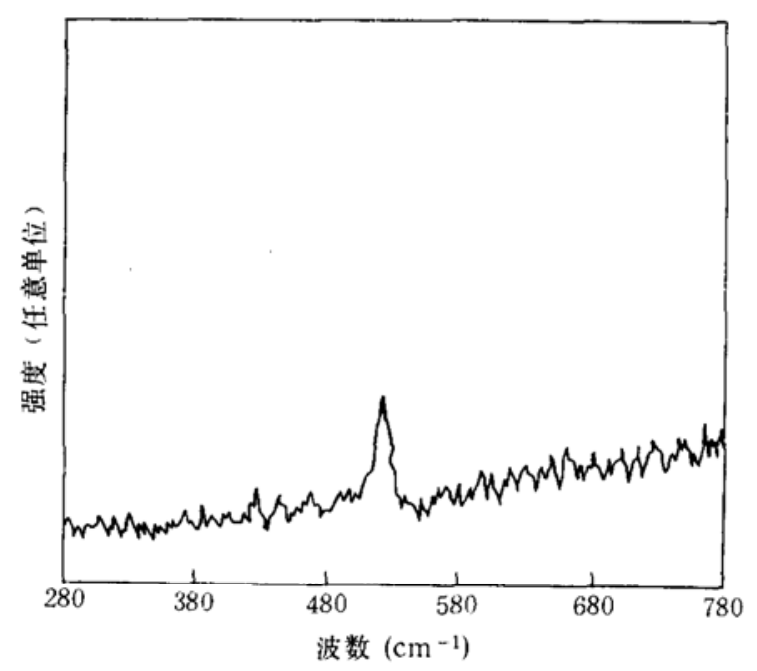

图 2 多孔硅样品 Raman 散射光谱

1 为多孔硅光致发光光诸; 2 为从发光的多孔硅表 面分离下来的粉末的光致发光光谱; 3 为硅片末抛 光面上制备的多孔硅光致发光光谱

图 1-2 为从多孔硅样品表面分离下的粉末光致发光光谱, 光谱峰值位置在 $17000 \mathrm{~cm}^{-1}$ $(588 \mathrm{~nm})$ 处, 半高宽为 $3480 \mathrm{~cm}^{-1}(122 \mathrm{~nm})$. 图 1-3 为在未抛光硅片表面上用同样的阳极氧化制 成的多孔硅样品光致发光光谱 (样品制备后 40 天测). 谱线峰值位置在 $16540 \mathrm{~cm}^{-1}(604 \mathrm{~nm})$ 处, 半高宽为 $3200 \mathrm{~cm}^{-1}(118 \mathrm{~nm})$.

图 3(a) 为用扫描电镜摄制的多孔硅样品表面形貌显微照片, 从照片中可以看到, 在样品表 面层脱落处密集、均匀地分布着大量的微孔. 图 3(b) 为分析多孔硅样品截面微结构扫描电镜 照片, 从照片中可以看到清晰的微孔长达近 $100 \mu \mathrm{m}$, 样品可分成三层: 表面层、多孔层、硅单晶 衬底层.

图 4 为分析荧光粉末形貌扫描电镜照片. 图 4(a) 为研磨前粉末形貌显微照片; 图 4(b) 为 研磨后荧光粉末形貌显微照片. 从照片中可以看到, 不管研磨前后, 粉末样品均观察不到微 

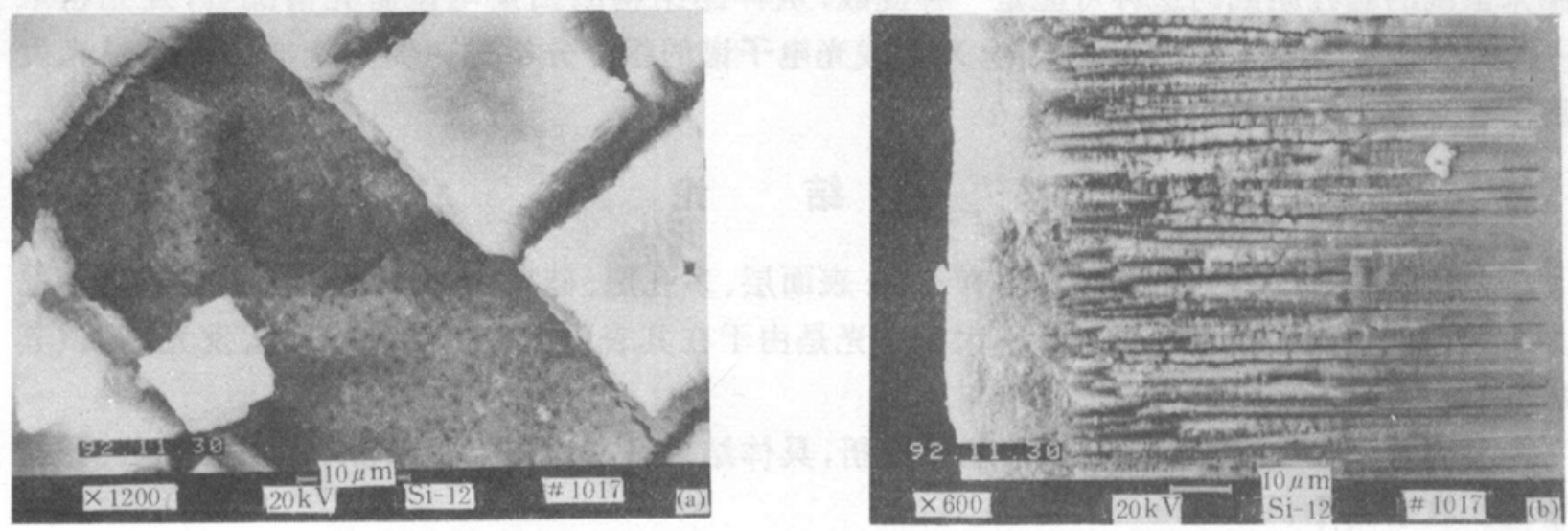

图 3 多孔硅样品表面形貌、截面结构 SEM 照片

(a)多孔硅样品表面形貌 SEM 照片; (b)多孔硅样品截面结构 SEM 照片
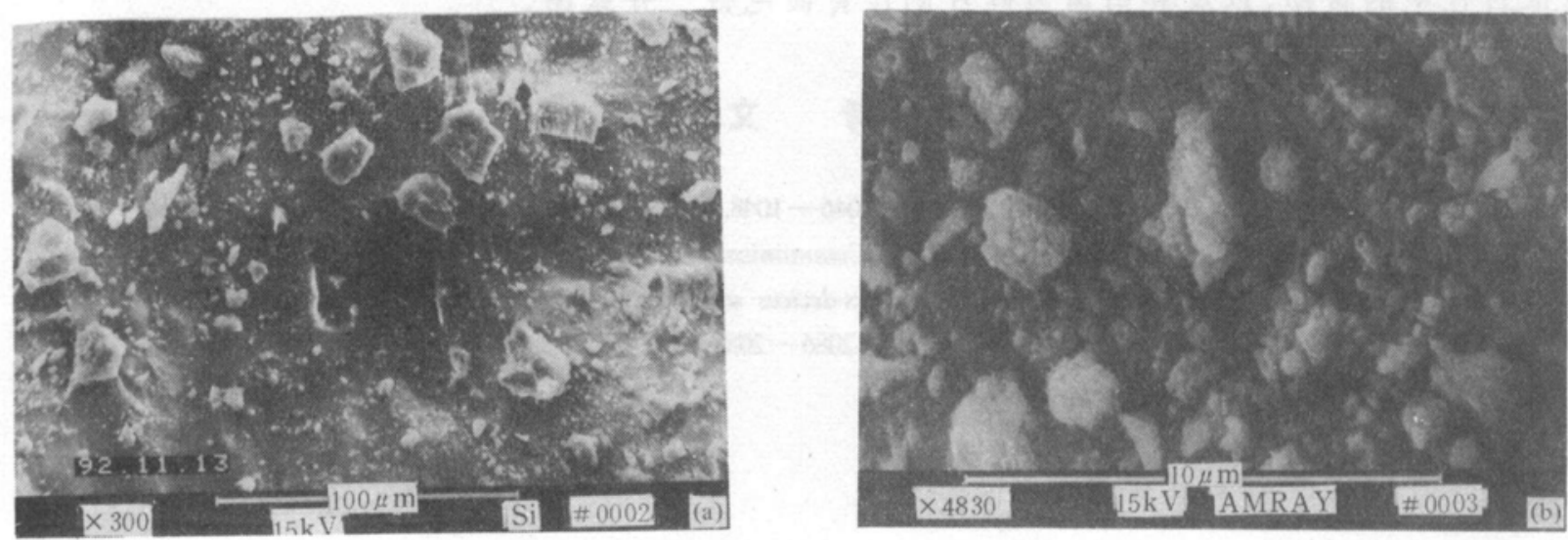

图 4 苂光粉末形貌、结构 SEM 照片

(a) 研磨前粉末 SEM 照片; (b) 研磨后粉末 SEM 照片

柱状结构迹象, 研磨后的粉末有团聚情况.

图 5 为用 $X$ 射线光电子谱对发光多孔 硅样品表面所进行的组分分析记录, 从谱 图中可以看到样品表面主要含有 $\mathrm{Si}, \mathrm{O}, \mathrm{C}$, $\mathrm{F}$, 其中的 $\mathrm{Si}$ 原子数只占 $52.72 \%(\mathrm{C}$ : $33.43 \%$, O: $13.04 \%$, F: $3.26 \%$ ).

从图 1-1, 2 谱线具有相近的峰值位置、 半高宽和线形可知,多孔硅表面所发出的可 见光来自样品制备过程中形成的位于表面 的黄色粉末状物质; 从图 1-3 中硅片未抛光 面上的实验看来, 样品发光与否同硅片表 面是否抛光无关. 而粉末状荧光粉研磨后 仍能发出同样的可见光, 对发光粉末是由

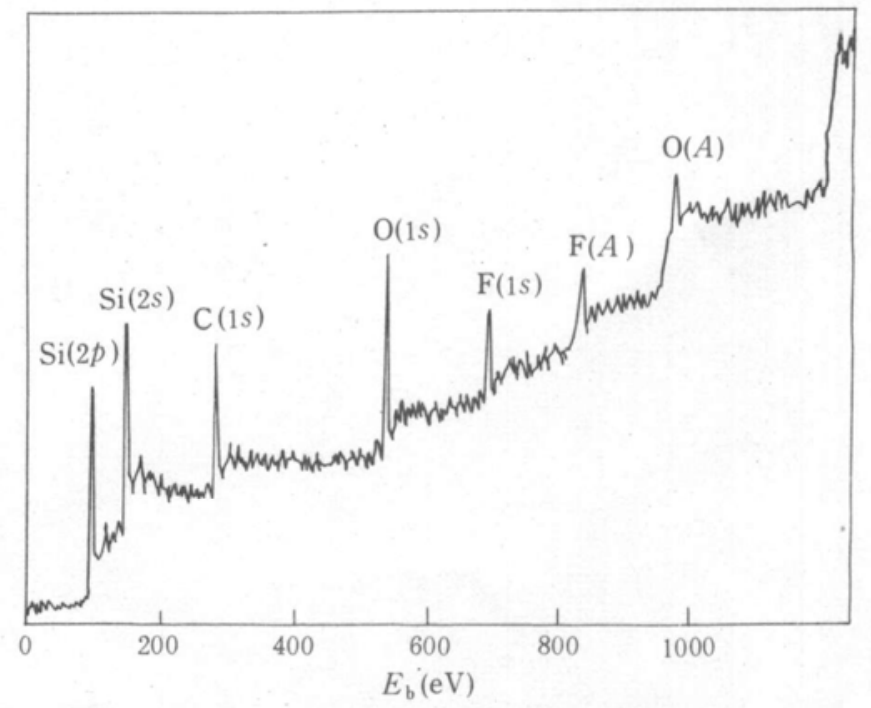

图 5 多孔硅样品表面组分 XPS 分析谱 
纳米量级的硅柱组成的这种可能是一种挑战; 从样品结构的扫描电镜研究情况看, 发光粉末 一般形成于多孔层上面的表面层中; $X$ 射线光电子谱的组分分析进一步.支持样品的可见光发 射不是来源于纳米量级的硅柱.

\section{4 结 论}

多孔硅的高效可见光发射样品有三层: 表面层、多孔层、硅单晶衬底层. 样品的发光情况 与腐蚀前硅片表面是否拖光关系不大. 发光是由于在其表面产生了某种粉末状发光物质 (其 组分、结构可能很复杂).

我们对多孔硅发光样品已做了微区分析, 具体结果另文详述. 发光粉末的具体组分、结构 情况正在研究中.

致谢 作者对黄世华、于宝贵在光致发光光谱测试过程中的帮助,姜锦秀、刘乃康在 SEM 测试过程中的帮助, 以及具昌南为硅片制作背面电极一并致谢.

\section{参考文献}

[1] Canham, L. T., Appl. Phys. Lett., 1990, 57(10): 1046- 1048.

[2] Brandt, M. S., Fuchs, H. D. et al., Solid State Communication, 1992, 81(4): 307-312.

[3] Nobuyoshi Koshida, Hideki Koyama, Optoelectronics-devices and Technologies, 1992, 7(1): $103-115$.

[4] Sui Zhi-fen et al., Appl. Phys. Lett., 1992, 60(17):2086-2088. 